\title{
TRASCENDER El ESPACIO DE PODER. HACIA UNA CARACTERIZACIÓN DE LAS ESCAlAS de ACCIÓn EN LA Alta EdAd MEdia ENTRE las CUENCAS Del CEA Y DEL Pisuerga*
}

\author{
Álvaro Carvajal Castro \\ Universidad de Salamanca
}

RESUMEN: Los conceptos de escala y cambio de escala, tal y como han sido recientemente introducidos en la historiografia altomedieval, han abierto nuevas vias desde las que profundizar en el estudio de las relaciones socioespaciales medievales. En este sentido, este artículo comienza por reconsiderar el término «espacio de poder» para, a partir de ahí, proponer la idea de «escala de acción» como herramienta de análisis complementaria. En la segunda parte se desarrollará la aplicación del concepto al estudio de una región que hasta el momento había sido tan solo parcialmente recogida en los trabajos sobre los territorios meseteños al norte del Duero: el espacio entre las cuencas del Cea y del Pisuerga y la zona inmediatamente al sur de este ámbito en los siglos Xy XI. Para ello, se analizará una selección de casos representativos que permitirán identificar algunos de los elementos constitutivos de las escalas de acción de distintos sujetos sociales: la uni-

\footnotetext{
Álvaro Carvajal Castro es investigador en formación adscrito al Dpto. de Historia Medieval, Moderna y Contemporánea de la Universidad de Salamanca. Dirección para correspondencia: Departamento de Historia Medieval Moderna y Contemporánea, Facultad de Geografia e Historia de la Universidad de Salamanca, c/ Cervantes, s/n, 37002 Salamanca. Correo electrónico: carvajal@usal.es.

* Este trabajo se ha realizado con la financiación de una ayuda del Programa de Formación del Profesorado Universitario (FPU) del Ministerio de Educación y Ciencia. Quiero dejar constancia de mi agradecimiento a aquellas personas que leyeron versiones previas de este texto, ya que con sus comentarios y críticas han contribuido a enriquecerlo. De manera especial, me gustaría reconocer el apoyo de José María Mínguez, Iñaki Martín Viso e Isaac Martín Nieto.

Abreviaturas: HeRrero DE LA Fuente, Marta, Colección Diplomática del Monasterio de Sahagún (857-1230), II (1000-1073), León, Centro de Estudios San Isidoro, 1988 (CDS II); MíngueZ, José María, Colección diplomática del Monasterio de Sahagún (siglos IX y X), León, Centro de Estudios San Isidoro, 1976 (= CDS, I).
} 
dad doméstica campesina, las comunidades campesinas, las élites locales, los monasterios y los grandes grupos aristocráticos.

Palabras Clave: Escala de acción. Espacio. Poder. Relaciones sociales. Alta Edad Media. Meseta del Duero.

Beyond the Space of Power. Towards a Characterization of the Scales of ACtion In The Territories between the Rivers CeA ANd Pisuerga IN THE $10^{\text {Th }}$ AND $11^{\mathrm{TH}}$ CENTURIES

ABSTRACT: The concepts of scale and scale change, as they have recently been introduced in Early Medieval historiography, have opened new ways for the historical understanding of medieval socio-spatial relations. Following this line of thought, this article reviews the concept of «space of power» in order to propose the idea of «scale of action» as a complementary analytical tool. The second part develops its use through the analysis of a region that has so far been only partially considered within the framework of studies on the territorial organization of the Duero plateau: the lands between the rivers Cea and Pisuerga and the area to its south in the $10^{\text {th }}$ and $11^{\text {th }}$ centuries. To do so, a selection of representative case studies will be analysed in order to identify some of the constitutive elements of the scales of action of different social agents: peasant domestic units, peasant communities, local elites, monasteries and large aristocratic groups.

KEY WORDS: Scale of action. Space. Power. Social relations. Early Middle Ages. Duero plateau.

\section{INTRODUCCIÓN}

En el año 1056, Marcos y su mujer Emderia vendieron al abad Martín una serie de bienes ${ }^{1}$. Entre ellos se encontraba media viña que Marcos había comprado a Álvaro Ferriz. Mediante esta adquisición, Marcos había ampliado las tierras bajo su propiedad. En otras palabras, había producido un espacio físicamente reconocible en el que manifestaba su capacidad para llevar a cabo esa acción. Las formulaciones tradicionales sobre la organización social del espacio han tendido a obviar casos como este; casos que, sin embargo, entrañan una acción significativa sobre el espacio. La conceptualización tradicional de determinados ámbitos geográficos y sociales como espacios de poder - valles, aldeas, villas, ciudades, etc.- , que ha tendido a identificar estas estructuras espaciales con la acción de las clases dominantes, relega a un segundo plano la capacidad de acción de quienes se vieron sometidos a estos marcos, lo que plantea dificultades a la hora de analizar los procesos formati-

1 CDS II, doc. 584. 
vos que dieron lugar a dichas estructuras ${ }^{2}$. Dada la importancia que el análisis del espacio y de los fenómenos de poder tiene en nuestra comprensión de la Alta Edad Media, es necesario seguir buscando herramientas metodológicas que nos permitan profundizar en el estudio del espacio medieval de manera más completa. En este sentido, el objetivo de este artículo es plantear una vía complementaria desde la que caracterizar, en términos de escala ${ }^{3}$, los ámbitos espaciales en los que se desarrollaba la acción de los sujetos medievales, fueran individuales o colectivos, e independientemente de su posición social, como base para una reconsideración del proceso de formalización de las relaciones de poder en el espacio.

La compraventa de Marcos y Emderia tuvo lugar en un ámbito geográfico, el que hoy representan la provincia de Palencia y el norte de la de Valladolid, que había quedado en gran medida al margen de los estudios sobre las estructuras territoriales y el poblamiento del norte de la Meseta de las últimas dos décadas ${ }^{4}$. A partir de los planteamientos teóricos y metodológicos que se exponen en la primera parte del artículo, en la segunda parte se presentará el análisis de una serie de casos representativos de las distintas escalas de acción que se pueden distinguir en la región en el siglo $\mathrm{X}$ y los dos primeros tercios del siglo XI: la unidad doméstica campesina, el ámbito de interacción campesina, la escala de acción de las élites locales, los dominios monásticos y, aunque de manera parcial, los grandes dominios aristocráticos. El objetivo es explorar su caracterización en términos de escala, lo que podría servir como base para un análisis dinámico de las transformaciones territoriales que se

2 Hay que reconocer, no obstante, que tanto el concepto como los estudios que lo han desarrollado tienen una gran importancia para nuestra comprensión de la sociedad medieval, de lo que dan buena cuenta, por ejemplo, los trabajos recogidos en IGLESIA DUARTE, José Ignacio de la (coord.), Los espacios de poder en la España Medieval, Logroño, Instituto de Estudios Riojanos, 2002.

3 Vid. infra.

4 En la línea de estudios como, sin ánimo de exhaustividad, Álvarez Borge, Ignacio, Monarquía feudal y organización territorial. Alfoces y merindades en Castilla (siglos X-XIV), Madrid, CSIC, 1993; SÁNCHEZ BADIOLA, Juan José, La configuración de un sistema de poblamiento y organización del espacio: el territorio de León, León, Universidad de León, 2002. Igualmente relevantes: MARTíN VISO, Iñaki, Poblamiento y estructuras sociales en el norte de la Península Ibérica (siglos VI-XIII), Salamanca, Universidad de Salamanca, 2000; Escalona, Julio, Sociedad y Territorio en la Alta Edad Media Castellana. La formación del Alfoz de Lara, Oxford, B.A.R., 2002. Hay que destacar el trabajo realizado por Carlos M. Reglero de la Fuente para el entorno de los Montes de Torozos, zona que se corresponde con el sur del ámbito geográfico que se contempla aquí. Véanse REGLERO DE LA FUENTE, Carlos M., Los señoríos de los Montes de Torozos. De la repoblación al Becerro de las Behetrías (siglos X-XIV), Valladolid, Universidad de Valladolid, 1993; REGLERO DE LA FUENTE, Carlos M., Espacio y poder en la Castilla Medieval. Los Montes de Torozos (siglos X-XIV), Valladolid, Diputación Provincial de Valladolid, 1994. 
aprecian a finales del periodo asturleonés y que se concretarán a partir del reinado de Fernando $\mathrm{I}^{5}$. Esto último, sin embargo, deberá ser objeto de otro trabajo.

\section{LA ESCALA DE ACCIÓN COMO PROPUESTA METODOLÓGICA}

Si antes he hablado de fenómenos de poder es porque en este artículo el interés no se centra en las nociones sociológicas de poder, sino que toma como punto de partida las manifestaciones de su ejercicio, con el objetivo de profundizar en la valoración de la capacidad de acción de los distintos sujetos sociales. En este sentido, J.A. García de Cortázar, en un artículo dedicado a la caracterización historiográfica y metodológica de los espacios de poder, atribuyó seis competencias a los «titulares de poder». Estas incluían las capacidades de dictar normas; de designar personas encargadas de su cumplimiento; de ejercer facultades judiciales, militares o fiscales; de disponer de una imagen del poder; de proyectar el poder de forma material; y de proyectarlo de forma inmaterial ${ }^{6}$. La lista es muy interesante por dos razones. La primera es su carácter comprehensivo, ya que incluye elementos relacionados con la capacidad de control sobre lo material, con el ejercicio de la autoridad y con la representación y legitimación del ordenamiento social establecido. La segunda es que parte de un interés por caracterizar las capacidades de los «sujetos activos» $\rangle^{7}$ que abre la puerta - lo que no quiere decir que J.A. García de Cortázar lo formulara así- a la posibilidad de profundizar en la propuesta mediante el recurso a la teoría de la agencia (agency $)^{8}$.

5 Este trabajo complementa la revisión del desarrollo de las grandes entidades políticas de la región del siglo X - los dominios de los Banu Gómez y el condado de Monzón-, que se ha realizado en otro lugar: CARVAJAL CASTRO, Álvaro, «Superar la frontera: Mecanismos de integración territorial entre el Cea y el Pisuerga en el siglo X», Anuario de Estudios Medievales (en prensa).

6 GARCía DE CORTÁzAR, José Ángel, «Elementos de definición de los espacios de poder en la Edad Media», en IGLESIA DUARTE, José Ignacio de la (coord.), Los espacios de poder en la España Medieval, Logroño, Instituto de Estudios Riojanos, 2002, págs. 26-35.

7 GARCÍA DE CORTÁZAR, «Elementos de definición de los espacios de poder», pág. 23.

8 Según A. Giddens: «Agency refers not to the intentions people have in doing things but to their capability of doing those things in the first place (which is why agency implies power)... [it] concerns events of which an individual is the perpetrator, in the sense that the individual could, at any phase in a given sequence of conduct, have acted differently» (GIDDENS, Anthony, The Constitution of Society. Outline of the Theory of Structuration, Cambridge, Polity Press, 1984, pág. 9). Véanse también HODDER, Ian, «Agency and individuals in long-term processes», en DOBRES, Marcia-Anne y RoBB, John E. (eds.), Agency in archaeology, Londres, Routledge, 2000, págs. 22-23, con más énfasis en los recursos que hacen posible la acción; y JONES, Andrew, Archaeological theory and scientific practice, Cambrigde, Cam- 
A pesar de ello, la lista plantea un problema metodológico, ya que anticipa un grado de institucionalización y formalización de las relaciones de dominio que, aunque se corresponde con determinadas manifestaciones del desarrollo estructural de la sociedad medieval, oscurece el proceso de formalización de dichas relaciones ${ }^{9}$. Hay que tener en cuenta que su imposición no fue exclusivamente fruto de un impulso nacido de las élites, sino que, como demuestra, por ejemplo, el carácter negociado de los fueros o de la resolución judicial de las disputas, surgió de una relación dialéctica en la que entraban en juego las capacidades de acción de múltiples actores ${ }^{10}$. Una aproximación dinámica necesita, por tanto, hacer significativa, en cada contexto concreto y en el marco del proceso histórico general, la capacidad de acción tanto de los grupos dominantes como de los subordinados.

En este sentido, un primer paso consistiría en jerarquizar conceptualmente los elementos incluidos en esa lista de capacidades. De entre ellas, dos se pueden considerar como fundamentales. La primera es la capacidad de proyección material del poder, que según J.A. García de Cortázar se plasmaba en la construcción de una residencia señorial y en «la ordenación del espacio de generación de recursos susceptibles de apropiación» ${ }^{11}$. Hay que tener en cuenta que, en el periodo altomedieval, el ejercicio del poder dependía en gran medida de la capacidad de movilizar recursos materiales ${ }^{12}$. La segunda es la proyección inmaterial del poder, que se definía como la «pervivencia del mismo en las mentes de las personas sujetas a sus titulares» a través del mantenimiento de un imaginario de ordenación de la sociedad y del control de lo

bridge University Press, 2002, pág. 20, para una definición que pone el acento en el papel de la agencia en la producción y reproducción de las estructuras sociales.

9 Una interpretación dinámica de los procesos de complejización social permite distinguir analíticamente los momentos de emergencia de los distintos elementos de la dominación. Una caracterización breve en Runciman, Walter G., A Treatise on Social Theory, Cambridge, Cambridge University Press, 1989, vol. II, págs. 148-155. Véase MANN, Michael, The Sources of Social Power, vol. 1. A history of power from the beginning to A.D. 1760, Cambridge, Cambridge University Press, 1986, págs. 34-72, y CHAPMAN, Robert, Archaeologies of Complexity, Londres, Routledge, 2003, para una revisión crítica de distintos modelos y bibliografía.

${ }_{10}$ ALFONSO ANTÓN, Isabel, «Campesinado y derecho: la vía legal de su lucha (Castilla y León, siglos X-XIII)», Noticiario de Historia Agraria, 13 (1997), págs. 15-31; ALfONSO ANTÓN, Isabel, «La contestation paysanne face aux exigences de travail seigneuriales en Castille et León. Les formes et leur signification symbolique», en BOURIN, Monique y MARTíNEZ Sopena, Pascual (eds.), Pour une anthropologie du prélèvement seigneurial dans les campagnes médiévales (XIe-XIVe siècles). Réaliés et représentations paysannes, París, Publications de la Sorbonne, 2005, págs. 291-320.

11 GARCÍA DE CORTÁZAR, «Elementos de definición de los espacios de poder», pág. 31.

12 Un ejemplo son esas políticas de la tierra descritas en WICKHAM, Chris, Framing the Early Middle Ages. Europe and the Mediterranean, 400-800, Oxford, Oxford University Press, 2005, pág. 58 . 
escrito $^{13}$. La imagen del poder, que es otra de las capacidades incluidas en la lista, solo podía cobrar sentido en el marco, o como parte, de un sistema más amplio de legitimación de lo establecido.

A partir de aquí podríamos reformular estos dos elementos básicos para obtener un criterio sobre el que basar una aproximación transversal a las capacidades de acción de los distintos sujetos sociales. En primer lugar, es innegable que una residencia señorial tenía unas implicaciones sociales diferentes de las de una casa campesina. No obstante, el punto de partida de ambos supuestos radica en el reconocimiento de que todos los actores podían, en principio, plasmar materialmente en el espacio su capacidad de acción. En este sentido, la compra de la viña produjo un espacio físicamente reconocible, definido por los derechos que Marcos tenía sobre el mismo. Esto supone reconocer que diferentes sujetos, aunque condicionados por sus distintas posibilidades, podían producir diversas ordenaciones del espacio. En segundo lugar, podríamos redefinir la idea de proyección inmaterial como la capacidad de tener un impacto sobre los mecanismos que, en distintos niveles, hacían posible que una acción fuera reconocida como legítima por el resto de actores implicados. Esto incluiría, por ejemplo, los mecanismos de memoria social sobre los que se asentaba el reconocimiento de los derechos de los que una persona o una comunidad disfrutaban sobre sus tierras ${ }^{14}$. Si sabemos que Marcos compró una viña a Álvaro Ferriz es porque la formalización de su posterior venta al abad Martín activó la necesidad de rememorar la transacción inicial. De esta forma se confirmaban los derechos de Marcos sobre la misma y, por lo tanto, se reafirmaba su capacidad para transmitirlos al monasterio. Podemos, pues, decir que la primera compraventa generó una memoria a la que se asociaron los derechos de Marcos sobre la viña y que era reconocida por otros actores.

Un tercer paso consistiría en establecer un criterio para valorar los recursos económicos y sociales ${ }^{15}$ que hacían posible que un sujeto llevara a cabo una

13 GARCÍA DE CORTÁZAR, «Elementos de definición de los espacios de poder», págs. 32-33.

14 Fentress, James y WickHAM, Chris, Social Memory, Oxford, Blackwell, 1992; ALFONSO ANTÓN, Isabel, «Memoria e identidad en las pesquisas judiciales en el área castellanoleonesa medieval», en JARA FuENTE, José Antonio, MARTin, Georges y ALFONSO ANTÓN, Isabel (eds.), Construir la identidad en la Edad Media, Cuenca, Ediciones de la Universidad de Castilla-La Mancha, 2010, págs. 249-279.

15 En términos de capital social, definido como la «posesión efectiva de una red de relaciones de parentesco (u otras) susceptibles de ser movilizadas o, por lo menos, manifestadas» (Bourdieu, Pierre, El sentido práctico, Buenos Aires, Siglo XXI, 2007, págs. 59, n. 9). Asumo el concepto sin recurrir de manera estricta a la noción de «red de relaciones». Considero más útil, para el caso que nos ocupa, la forma en que se han abordado preocupaciones similares - como puede ser el funcionamiento de las redes de patronazgo, entre otras cuestionesen trabajos como DAVIES, Wendy, Small Worlds. The Village Community in Early Medieval 
acción. El término «espacio de poder» hacía referencia a los espacios en los que se plasmaban las estructuras en cuyo marco se organizaban los recursos materiales y sociales de los que disfrutaban algunos sujetos, por lo que sigue siendo útil para conceptualizar determinadas estructuraciones socioespacia$l^{1} s^{16}$. No obstante, plantea dificultades a la hora de analizar su proceso formativo, ya que parte de una noción de organización social del espacio basada en una secuencia lógica en la que la estructura social es anterior a la estructuración del espacio ${ }^{17}$. Sin embargo, deberíamos valorar en qué medida y cómo el espacio, en su dimensión física, puede condicionar las relaciones sociales ${ }^{18}$. ¿Cómo podríamos entonces conceptualizar el espacio de manera que, al abordar su estudio, reconozcamos en él los recursos que condicionan la capacidad de acción de los distintos sujetos sociales y valorar el papel que juega, ya sea en la emergencia o en la estructuración de relaciones sociales?

Distintas propuestas desde la geografía, la sociología, la arqueología o la antropología, han insistido en que es necesario entender el espacio como un producto social ${ }^{19}$. A partir de esta idea, autores como E. Soja plantean el carácter dual de las estructuras espaciales, esto es, las conciben a la vez como el resultado y como el medio de las prácticas cotidianas que producen y reproducen las relaciones sociales ${ }^{20}$. Además, analizan el espacio en su doble di-

Brittany, Londres, Duckworth, 1988; WiCKHAM, Chris, The mountains and the city: The Tuscan Apenines in the early Middle Ages, Oxford, Clarendon Press, 1988; INNES, Matthew, State and Society in the Early Middle Ages. The Middle Rhine Valley 400-1000, Cambridge, Cambridge University Press, 2000; JARRETT, Jonathan, Rulers and Ruled in Frontier Catalonia, 880-1010, Woodbridge, The Boydell Press, 2010. Debo precisar que todos ellos se realizaron sobre conjuntos documentales mucho más densos de los que tenemos para la zona de estudio propuesta. Por ello, en lo que respecta a este trabajo, su valor no reside tanto en su método, sino en su orientación metodológica. Se pueden, además, utilizar como modelos hipotéticos sobre los que intentar articular una explicación para aquellos casos en los que la documentación es más escasa.

16 Vid. n. 8.

17 García de CORTÁzAR, José Ángel, «Organización social del espacio: propuestas de reflexión y análisis histórico de sus unidades en la España Medieval», Studia Historia. Historia Medieval, 6 (1988), págs. 195-196.

18 Por ejemplo, tal y como se refleja en DAVIES, Small Worlds, pág. 125. Otro ejemplo en las consideraciones de $\mathrm{C}$. Wickham con respecto a los espacios de montaña en WiCKHAM, The mountains and the city, especialmente págs. 3-5 y 357-365.

19 La base de esta noción en LefEBVRE, Henri, La production de l'espace, París, Anthropos, 2000 [1974].

20 SoJA, Edward W., Postmodern Geographies. The Reassertion of Space in Critical Social Theory, Londres, Verso, 1989. Esta noción está íntimamente ligada al concepto de «dualidad de la estructura» (GIDDENS, The Constitution of Society, pág. 24). En otros términos, en Godelier, Maurice, Lo ideal y lo material, Madrid, Taurus, 1989; GodeliER, Maurice, L'enigme du don, París, Fayard, 1997. Desde la arqueología, C. Tilley enfatiza el carácter 
mensión, a un mismo tiempo física y relacional —en tanto que entramado de relaciones sociales y simbólicas ${ }^{21}$ - Con ello ponen el énfasis en el carácter estructurador de la acción humana en el espacio, lo que permite hablar ya no solo de estructuras, sino de procesos dialécticos de estructuración de las relaciones sociales en el espacio. En definitiva, sus propuestas profundizan en la comprensión del espacio no como una mera plasmación de las relaciones sociales, sino como un elemento constitutivo de las mismas.

Sobre esta base, la noción de escala nos permite avanzar en el reconocimiento de la capacidad de acción de los distintos sujetos sociales en el espacio. El término se ha introducido en los últimos años en la historiografía sobre la alta Edad Media y su operatividad se ha ensayado para el estudio de distintos casos, lo que se podría tomar como indicio de su alto potencial como herramienta de análisis ${ }^{22}$. Si bien la mayor parte de estos trabajos se han centrado en la noción de cambio de escala, la intención en este artículo es profundizar en la comprensión y caracterización de la escala en sí misma y, en particular, en el concepto de escala de acción. Para ello, y en base a distintas propuestas realizadas desde la geografía, utilizaré, como definición de trabajo, la idea de escala de acción como una estructuración social del espacio, geográfica e históricamente particularizada, que determina las posibilidades y limitaciones de acción de un individuo, de un conjunto de individuos, o de otro tipo de actor social — por ejemplo, un monasterio ${ }^{23}$ - . Dicha estructura-

conflictivo del espacio (TILlEY, Christopher, A phenomenology of Landscape. Place. Paths and Monuments, Oxford, Berg, 1994, págs. 10-11).

21 Para Edward. W. Soja la estructura espacial es «a dialectically defined component of the general relations of production, relations which are simultaneously social and spatial» (SoJA, Edward W., "The Socio-Spatial Dialectic», Annals of the Association of American Geographers, 70/2 (1980), pág. 208. Sobre la dimensión relacional: BRIGHENTI, Andrea, «On Territoriology. Towards a General Science of Territory», Theory, Culture and Society, 27/1 (2010), págs. 52-72. Véase también TILlEY, A phenomenology of Landscape.

22 Los trabajos de Julio Escalona son la principal referencia. E.g.: EscAlONA, Julio, «Mapping Scale Change: Hierarchization and Fission in Castilian Rural Communities during the Tenth and Eleventh Centuries», en Davies, Wendy, Halsall, Guy y ReYNOLDS, Andrew, People and Space in the Middle Ages, Turnhout, Brepols, 2006, págs. 143-166; EscALONA, Julio, «Patrones de fragmentación territorial: el fin del mundo romano en la Meseta del Duero», en Espinosa Ruiz, Urbano y Castellanos, Santiago (eds.), Comunidades locales y dinámicas de poder en el norte de la Península Ibérica durante la Antigüedad Tardía, Logroño, Universidad de la Rioja, 2006, págs. 165-199. Una revisión teórica y bibliografíca en ESCALONA, Julio, «The Early Middle Ages: A Scale-Based Approach», en EsCALONA, Julio y REYNOLDS, Andrew (eds.), Scale and Scale Change in the Early Middle Ages, Turnhout, Brepols, 2011, págs. 9-30. Se pueden ver varios ejemplos de aplicación de los conceptos de escala y cambio de escala en EsCALONA, Julio y REYNOLDS, Andrew (eds.), Scale and Scale Change in the Early Middle Ages, Turnhout, Brepols, 2011.

23 A partir de las definiciones y caracterizaciones de la escala de SMITH, Neil y DENNIS, Ward, «The Restructuring of Geographical Scale: Coalescence and Fragmentation of the Northern Core Region», Economic Geography, 63/2 (1987), págs. 160-182; MARSTON, Sallie 
ción sería, en su dimensión relacional, el resultado y medio de la producción y reproducción de las relaciones sociales de las que el actor o actores participan: es, por tanto, una realidad dinámica en la que se estructuran los recursos sociales de los que puede disfrutar un actor. La particularización geográfica se introduce para resaltar la dimensión material de la escala ${ }^{24}$ y para llamar la atención sobre el hecho de que cada estructuración social se desarrolla en el marco de un determinado espacio natural, cuya apropiación, y en el que la producción de recursos económicos, resulta de la relación que exista entre las características del propio espacio natural, la percepción y construcción social del mismo, y la estructuración social que alberga ${ }^{25}$.

Además, hay que tener en cuenta que un mismo espacio y un mismo sujeto pueden constituir elementos de más de una escala, por lo que las relaciones dialécticas entre escalas juegan un papel fundamental en cada configuración escalar particular. Por ejemplo, un campesino puede actuar dentro de su propia escala, definida por las propiedades que le permiten producir recursos económicos y por su capital social. A la vez, la obligación de realizar el pago de una renta podría convertirlo en un elemento constitutivo de la escala de acción de un dominio monástico, en la medida en que la capacidad de acción del monasterio estuviera condicionada por los recursos derivados de la percepción de rentas. También puede ocurrir que los sujetos intenten movilizar los diferentes recursos que les ofrecen las distintas escalas de acción de los que participan ${ }^{26}$. Tal sería el caso, por ejemplo, de una comunidad local que recurriera al rey para la resolución de una disputa.

En definitiva, el lenguaje de la escala podría permitirnos reconocer las acciones concretas como indicios ${ }^{27}$ de prácticas y lógicas ${ }^{28}$ de producción y re-

A., «The Social Construction of Scale», Progress in Human Geography, 24/2 (2000), págs. 219-242; PAASI, Anssi, «Place and region: looking through the prism of scale», Progress in Human Geography, 28/4 (2004), págs. 536-546.

24 MARSTON, «The Social Construction of Scale», pág. 221.

25 SoJA, Postmodern Geographies, p. 121. Esto nos acerca a la idea de construcción social de la realidad espacial (en línea con los clásicos planteamientos de BERGER, Peter L. y Luckmann, Thomas, The Social Construction of Reality. A Treatise in the Sociology of Knowledge, Londres, Penguin Books, 1991 [1967]), que convendría explorar con más detenimiento para cuestiones relacionadas con la percepción y representación del espacio.

26 Un ejemplo en términos de escala en EsCALONA, Julio, «Conflicto religioso y territorialidad en un mundo en fragmentación: un ensayo comparativo del noroeste hispánico y Britania en los siglos IV-VI», en CASTELlanOS, Santiago y MARTín VISO, Iñaki (eds.), De Roma a los bárbaros: poder central y horizontes locales en la cuenca del Duero, León, Universidad de León, 2008, págs. 171-203.

27 GinZBURG, Carlo, «Indicios. Raíces de un paradigma de inferencias indiciales», en GinzBURG, Carlo, Mitos, emblemas, indicios. Morfología e historia, Barcelona, Gedisa, 1994, págs. 138-175.

28 El término «lógica» se usa a menudo en la historiografía sin un contenido teórico explícito. Su utilización historiográfica deriva en gran medida de las aportaciones realizadas en 
producción de estructuraciones socioespaciales particulares y ver cómo, a través de distinta prácticas sociales, informales o institucionalizadas, se establecían las relaciones entre escalas. Metodológicamente, nos ayudaría a superar las dificultades que plantean aquellos casos para los que se dispone de poca información, pero para los que es necesario intentar articular un marco explicativo que permita insertarlos en un marco historiográfico más amplio. Además, permitiría profundizar en la complejidad de los espacios sociales sobre los que se asentaba la capacidad de acción de los distintos actores y, sobre todo, de quienes actuaban en las escalas de mayor complejidad, es decir, aquellas que englobaban las escalas de acción de otros actores. Pero esto conviene desarrollarlo mediante la aplicación de estos conceptos al análisis de algunos casos concretos.

\section{APLICACIÓn AL ESTUDIO de CASOS: LAS ESCALAS DE ACCIÓN EN EL INTER- FLUVIO CEA-PISUERGa EN LOS SIGLOS X-XI}

\section{La unidad doméstica campesina}

La venta que realizaron Marcos y Emderia forma parte de un pequeño grupo de tres compraventas - a las que se añadiría una donación - que tuvieron lugar entre distintas familias campesinas y Martín, quien era abad de San Ciprián ${ }^{29}$. Las referencias espaciales nos permiten situarlas en el mismo entorno geográfico. Todas ellas se llevaron a cabo en el plazo de unos pocos días, en diciembre de 1056. Esta coincidencia en el tiempo plantea una primera pregunta sobre el contexto inmediato en el que tuvieron lugar. Uno de los documentos, en el que Munio y su familia venden varias tierras a cambio de grano, un carnero y vino, nos informa de que aquel había sido un annus ma-

el marco de los estudios sobre el campesinado (e.g.: CHAYAnOv, Alexander V., La organización de la unidad económica campesina, Buenos Aires, Nueva Visión, 1985 [1925]; o SHANIN, Teodor, Naturaleza y lógica de la economía campesina, Barcelona, Anagrama, 1976). Aunque desarrollarlo escapa a las posibilidades de este artículo, creo necesario, puesto que haré uso del concepto, apuntar el sentido que pretendo darle en este texto. La lógica determinada de un actor o grupo de actores se podría definir como las expectativas que motivan y genera el flujo de la acción humana - las prácticas sociales reiteradas - en el contexto social del que participan dicho actor o actores; las expectativas pueden ser asumidas de manera tácita o pueden ser elaboradas de manera discursiva, a partir de la observación y racionalización de la vida cotidiana (véase GIDDENS, The Constitution of Society, pág. 24; LuHMAN, Niklas, Sistemas sociales. Lineamientos para una teoría general, Barcelona, 1998 [1984]).

29 CDS II, docs. 583, 584, 585 y 586. 
$l u s^{30}$. Una mala cosecha podía tener importantes consecuencias para una familia campesina, ya que podía poner en peligro su capacidad para alimentarse o volver a sembrar ${ }^{31}$. Los campesinos se habrían visto entonces obligados a acudir a otros actores - en este caso, San Ciprián - para conseguir recursos. El monasterio, por su parte, se podría haber aprovechado de la situación para comprar las tierras más baratas. Dentro de su discurso, la referencia al annus malus justificaría que la cantidad que pagó por las tierras no fuera mayor.

El origen de la precariedad campesina podía ser meramente coyuntural o podía deberse a factores más profundos. De hecho, estos mismos documentos nos dejan entrever algunas tendencias o elementos que podían amenazar la subsistencia o la reproducción de la unidad campesina. Por ejemplo, sabemos de al menos una práctica social que podía influir negativamente en la capacidad económica de los grupos campesinos: el reparto de la herencia. Aunque garantizaba una base material mínima para los descendientes, la división podía dar lugar a la atomización del patrimonio familiar. En el caso que nos ocupa, Marcos y Emderia tenían seis hijos, a cada uno de los cuales le habría correspondido, en principio, una parte de los bienes del matrimonio. La repartición de la propiedad transmitida habría podido limitar, al menos inicialmente, la capacidad de producción de los miembros de la siguiente generación, lo que habría podido condicionar su capacidad de subsistencia e incluso exponerlos a una mayor presión señorial ${ }^{32}$.

Por supuesto, no debemos establecer una relación causal directa entre el fenómeno de la partición por herencia y la precariedad campesina ${ }^{33}$. En primer lugar, porque la herencia no constituía de por sí un fenómeno que necesariamente hubiera de atomizar el patrimonio familiar, ya que para que esto ocurriera tenían que darse otras condiciones como, por ejemplo, que la familia tuviera más de dos descendientes y que todos ellos estuvieran en condición de recibir una porción. En segundo lugar, porque existían estrategias que podían evitar o reducir las consecuencias que se habrían derivado de una situación como esa. Una de ellas sería la ampliación del espacio cultivado mediante la roturación de nuevas tierras o la ampliación de aquellas que ya estaban en cultivo. No obstante, habría que considerar si esa puesta en cultivo de nuevos espacios respondía únicamente a una lógica campesina o bien estaba su-

30 CDS II, doc. 583.

31 Hay que recordar que en otros casos se identifican picos de compraventa en los meses de diciembre, abril y mayo, es decir, los de aprovisionamiento para el invierno y de sementera (un ejemplo en la Meseta en CARBAJO SERRANO, María José, «El monasterio de los santos Cosme y Damian de Abellar. Monacato y sociedad en la época astur-leonesa», Archivos leoneses, 81-82 (1987), pág. 184).

32 LARREA CONDE, Juan José, «Aldeas navarras y aldeas del Duero: notas para una perspectiva comparada», Edad Media. Revista de Historia, 6 (2003-2004), pág. 170.

33 Véase la advertencia en WicKHAM, Framing the Early Middle Ages, pág. 552. 
peditada a una iniciativa señorial ${ }^{34}$. Otra posibilidad era la de mantener ciertos bienes indivisos, de forma que varios miembros de la familia disfrutaran de los derechos sobre los mismos. Tello Vellítiz, su mujer Monnia y la sobrina de ambos, Vellida, habían recibido una viña y un pomar de su pariente Vela Nunniz $^{35}$. Podríamos pensar que este grupo familiar había intentado transmitir íntegramente una parte del patrimonio para reforzar sus derechos sobre las tierras e intentar garantizar un complemento productivo para la siguiente generación. La estrategia, en este caso, no habría resultado efectiva: Tello Vellítiz, Monnia y Vellida se vieron finalmente obligados a vender la viña y el pomar al monasterio de San Ciprián.

Los campesinos también podían recurrir a otros mecanismos de transacción de tierras para ampliar o mejorar la gestión de sus propiedades, como la compraventa y la permuta ${ }^{36}$. Mediante la compra de tierras podían ampliar el espacio que cultivaban e incrementar así su capacidad de producción, mientras que con la permuta podían organizar mejor la distribución de sus propiedades, por ejemplo, para diversificar la producción o los espacios productivos y minimizar los riesgos de una mala cosecha o para reducir los tiempos de desplazamiento y mejorar el rendimiento de su trabajo. A ello podríamos añadir el matrimonio, ya que, aunque en sí mismo no constituyera una transacción, la suma de las aportaciones de cada cónyuge podía dar lugar a explotaciones de mayor tamaño dependientes de la gestión de una unidad doméstica. La tierra que Marcos compró a Álvaro Ferriz había sido de la mujer de este, por lo que parece que el marido podía adquirir un cierto derecho de disposición sobre las tierras de la esposa. No obstante, el propio Marcos señaló que había recibido unas tierras de su padre y otras de su madre, lo que indica que los bienes no se fundían en una única unidad de propiedad.

Compraventa, permuta, herencia y matrimonio eran algunos de los mecanismos institucionalizados - en tanto que prácticas sociales recurrentes- de transmisión de la propiedad. Marcos aparece haciendo uso o participando de todas estas prácticas, lo que no significa que tuviera, a priori, la capacidad de recurrir a ellas de manera inmediata. ¿Cuál era la base sobre la que se asentaba su capacidad de acción? ¿En qué medida la posibilitaba y la limitaba? ¿Cómo repercutían sus acciones sobre dicha base? En primer lugar, debemos tener en cuenta los factores materiales. La capacidad de producción agrícola,

34 Por ejemplo, y aunque se escapa del periodo que estamos tratando, sabemos que, más adelante, la condesa Ildonza daría fueros a quienes poblaran su heredad en el valle de Trigueros. La explotación de esta tierra se habría desarrollado, en último término, en el marco de una iniciativa señorial (CDS II, doc. 893) (1092.03.29). Para estos aspectos, véase REGLERO DE LA FUENTE, Espacio y poder en la Castilla Medieval.

35 CDS II, doc. 586.

36 CDS II, doc. 584. 
que dependía de la extensión de las tierras cultivadas y de su productividad, condicionaba la capacidad económica de los campesinos. De ello dependía no solo su subsistencia, sino también su capacidad para hacer frente al resto de obligaciones sociales ${ }^{37}$, para intercambiar propiedades o para producir el excedente que les permitiera, por ejemplo, comprar nuevas tierras. La adquisición de propiedades y la consiguiente extensión del espacio cultivado habrían podido traducirse en una mayor capacidad de producción, incrementando así las posibilidades económicas. En segundo lugar, habría que considerar la posición que Marcos ocupaba en la sociedad local, es decir, su capital social. Este habría condicionado su capacidad de interactuar con otros sujetos, así como el tipo de relaciones que podía establecer con ellos. Además, y dado que la transacción de tierras podía servir para establecer nuevos vínculos o reforzar los antiguos ${ }^{38}$, una compraventa o una permuta podían contribuir a redefinir, ampliar o potenciar la red de relaciones de la que Marcos participaba.

La combinación de ambas dimensiones - social y material - representaría la escala de acción de Marcos. Una escala que, como hemos visto, comprende tanto la relación dialéctica de la actividad humana sobre el espacio natural —el trabajo de Marcos sobre la tierra- como la dialéctica propia de las relaciones sociales, y que se materializaba en la configuración espacial de las propiedades. Las posibilidades de acción dadas por dicha escala se hacían efectivas conforme a una lógica particular de gestión. Por ejemplo, se podría plantear, hipotéticamente, que Marcos, al realizar la permuta, buscaba optimizar el rendimiento de su trabajo mediante una reducción de los tiempos de desplazamiento o que, al comprar la viña, llevaba a cabo un intento consciente por ampliar su patrimonio para anular, o al menos suavizar, la tendencia a la fragmentación de la propiedad que conllevaba la herencia. Es evidente que no podemos afirmar nada acerca de los motivos que le impulsaron a llevar a cabo estas acciones, pero estas hipótesis nos permiten al menos reconocer la existencia de una acción orientada o justificada en función de la percepción de las consecuencias de las tendencias sociales a las que la unidad doméstica se encontraba sometida. Se trata de un paso hacia el reconocimiento de algunos de los elementos que conformaban la lógica que subyacía tras su acción. Una lógica que, así planteada, comprendería el objetivo de reproducir el modo de vida campesino, para lo cual era necesaria la conservación de unos niveles mínimos de propiedad. Sin embargo, incluía también la expectativa de la herencia o la posibilidad de enajenar tierras, lo que muestra su carácter contradictorio: el proceso de reproducción del modo de vida campesino entrañaba en sí mismo la reproducción de prácticas que podían ponerlo en peligro. En este caso,

37 Wolf, Eric, Peasants, Englewood Cliffs, N.J., Prentice-Hall, 1966, págs. 4-10.

38 WiCKHAM, The mountains and the city, pág. 6; AlFONSO ANTÓN, "Campesinado y derecho», pág. 26. 
la contradicción no se solucionó, como luego veremos, mediante elementos regulatorios propios de esta escala de acción, sino que constituyó la vía de inserción en otra escala.

Finalmente, hay que recordar que Marcos y Emderia realizaron la venta de manera al menos nominalmente conjunta. Aunque se ha podido caracterizar la acción de Marcos, poco se puede decir de la de Emderia. Aquí hemos visto que las mujeres podían participar de las compraventas, aunque aparecen siempre acompañadas de varones. Los documentos indican que podían recibir propiedades en herencia y que podían conservarlas y transmitirlas, pero no aparecen en otras ocasiones, como, por ejemplo, en las listas de testigos. ¿Cuál era su lugar en las relaciones sociales de producción y reproducción del ámbito doméstico? ¿Y el de los hijos e hijas? Aunque las fuentes no lo desvelen, hay que recordar que la unidad doméstica campesina comprendía las escalas de acción de todas las personas que la componían, y que no todas ellas lo hacían en condiciones de igualdad ${ }^{39}$.

\section{Interacción campesina, monasterios y poderes locales}

En el apartado anterior se presentó la unidad doméstica campesina abstraída de su medio social con el objetivo de caracterizarla como una escala de acción concreta. Sin embargo, algunos elementos indicaban ya que dicha escala no se puede entender de manera aislada, sino como parte de un contexto más amplio en el que participaba de distintos vínculos verticales y horizontales. De entre ellos, la permuta, la compraventa o el matrimonio evidenciaron las relaciones entre unidades domésticas diferenciadas. Esta interacción campesina podía dar lugar a una escala de acción particular. El caso del valle de la Cueza nos ayudará a iluminar algunos de sus elementos constitutivos ${ }^{40}$.

La primera referencia a este espacio la encontramos en una donación que Ramiro II realizó a Sahagún en el año $950^{41}$. Unos años después, en el año 984, García Gómez donó una heredad en la villa de Calzadilla, que se encontraba «in territorio de Carrione in valle de Quoza» ${ }^{42}$. Entre estas dos fechas,

39 Algo que se podría considerar partiendo, por ejemplo, de MeIllassoux, Claude, $M u$ jeres, graneros y capitales, México, Siglo XXI, 1999 [1975].

40 La excepcionalidad del valle de la Cueza en el contexto que estamos tratando justifica el interés de esta aproximación, a pesar de que, dada la carencia de una documentación más densa, habrá de ser necesariamente hipotética. Me remito por ello de manera especial a DAVIES, Small Worlds. Es muy interesante considerar también WICKHAM, Framing the Early Middle Ages, págs. 383-441, donde, a través del análisis de distintos casos, se plantean herramientas para el estudio comparado de distintas sociedades locales.

41 CDS I, doc. 129.

42 CDS I, doc. 318. 
los Banu Gómez habían intensificado su presencia en la zona, aunque hay que esperar hasta 1037 para ver a uno de ellos como conde en Carrión ${ }^{43}$. Tradicionalmente, se ha considerado que este grupo aristocrático ejercía un dominio uniforme sobre el conjunto de la cuenca del Carrión y que, hacia el último cuarto del siglo $\mathrm{X}$, sus miembros trasladaron su capital de Saldaña a Santa María de Carrión - hoy Carrión de los Condes ${ }^{44}$ —. Las fuentes, sin embargo, no muestran que existiera un dominio efectivo sobre todo ese ámbito territorial, por lo que es más interesante pensar en el progresivo afianzamiento de su capacidad de acción sobre esta zona a lo largo del siglo $\mathrm{X}^{45}$. En este contexto, resultaría plausible pensar que el valle de la Cueza, aparentemente independiente a mediados de siglo, hubiera sido integrado en el territorio de Carrión como resultado de la creciente presión que los Banu Gómez ejercían en el entorno. En todo caso, ¿por qué mantuvo su identidad territorial? ${ }^{46}$

Para entenderlo, es necesario profundizar en la historia del valle de la Cueza. Se trata de un territorio en el que no se aprecia la existencia de una centralidad definida, lo que contrasta con otros territorios de su entorno. Tan solo Castro Muza, que se asocia al yacimiento romano de Viminacium, en el entorno de la actual Calzadilla de la Cueza, podría haber ejercido una función central con anterioridad ${ }^{47}$, aunque a finales del siglo $\mathrm{X}$ parece que ya no lo hacía ${ }^{48}$. Por otro lado, sabemos que, en la primera mitad de este siglo, un personaje llamado Iunez Mohomatel había donado a Ramiro II unas villullis en la lomba de Cueza ${ }^{49}$. Unos años más tarde, en el 978, Bellido y Sarra vendieron a Sahagún su heredad en la Villa de Iunez Mohomatel ${ }^{50}$. Podríamos pen-

43 Además de la donación de García Gómez se conserva una donación de Osorio Díaz (CDS I, doc. 330). Gómez Díaz aparece como conde en Carrión alrededor de 1037 (CDS II, doc. 451).

44 Pérez Celada, Julio Antonio, «Sobre el origen de Carrión de los Condes y sus funciones en la articulación territorial: Del poblamiento vacceo a la configuración medieval», en RODRÍGUEZ COLMENERO, Antonio (coord.), Los orígenes de la ciudad en el noroeste hispánico. Actas del Congreso Internacional, Lugo, Diputación Provincial, 1998, págs. 1411-1424.

45 CARVAJAl CASTRO, «Superar la frontera».

46 Sobre territorialidad e identidad territorial, véase ESCALONA, Julio, «Territorialidades e identidades locales en la Castilla condal», en JARA FUENTE, José Antonio, MARTIN, Georges y Alfonso Antón, Isabel (eds.), Construir la identidad en la Edad Media, Cuenca, Ediciones de la Universidad de Castilla-La Mancha, 2010, págs. 55-82.

47 Siempre que fuera aplicable un modelo similar al propuesto en CASTELlanOS, Santiago y MARTíN VISO, Iñaki, «The local articulation of central power in the north of the Iberian Peninsula (500-1000)», Early Medieval Europe, 13/1 (2005), págs. 1-42.

48 CASTRO, Lázaro de, "Cerámicas romanas de Viminacium. Calzadilla de la Cueza (Palencia)», Sautuola, 1 (1975), págs. 251-265. En el siglo X era objeto de transacciones: el conde Osorio Gómez donó Castro Muza, que había obtenido mediante una compraventa, a Sahagún en el año 986 (CDS I, doc. 330).

49 CDS I, doc. 129.

50 CDS I, doc. 292. 
sar que la villa se correspondía con lo que unas décadas antes había sido la explotación de aquel propietario local. Además, en el año 977, Fortes y otros personajes vendieron unos bienes que lindaban con tres villas, dos de cuyos topónimos contenían nombres de persona, y con una propiedad que había sido de un tal Breto. La donación de Ramiro II a Sahagún consigna la existencia de un Valle Breto - lo no quiere decir que se tratara del mismo personajeasí como de un número relativamente amplio de villas de y valles de, seguidos de un antropónimo. Parcialmente, al menos, parecería que el espacio del valle de la Cueza estaba constituido por unidades espaciales de una entidad similar y que podrían corresponderse con las propiedades de ciertos individuos o grupos familiares ${ }^{51}$. Esta aparente uniformidad indicaría que podían existir unas condiciones que habrían favorecido la configuración de una sociedad local relativamente homogénea, en la que los vínculos horizontales surgidos entre las unidades menores de poblamiento habrían podido darle la suficiente cohesión como para mantener su identidad territorial frente a la imposición de una autoridad exterior ${ }^{52}$. La interpretación, por supuesto, no es tan sencilla, ya que la pauta territorial podría ser más compleja. En primer lugar, porque podían existir diferencias entre las unidades descritas. En segundo, porque podía haber propiedades de menor o mayor entidad en manos de personas o familias que no están documentadas. No obstante, la existencia de diferencias internas no contradeciría necesariamente la idea de una sociedad con una desigualdad social poco acusada, escasamente jerarquizada y relativamente homogénea. En tercer lugar, porque esta aparente homogeneidad no garantizaba que las relaciones sociales horizontales fueran lo suficientemente fuertes como para mantenerse ${ }^{53}$. De hecho, a partir del año 950 se constata la presencia de actores externos —el rey, Sahagún o los Banu Gómez-, así como de una élite aparentemente local que entra en las redes de patronazgo de estos últimos $^{54}$. Esto habría alterado el patrón local de relaciones sociales. No obstante, no deja de ser posible que en un momento anterior la realidad socioespacial del valle de la Cueza pudiera haber sido más compacta.

Los documentos apenas nos dejan profundizar en este aspecto, pero existen dos compraventas que reflejan la existencia de un entramado de relaciones sociales locales que podría acaso ser representativo de una realidad anterior.

51 Martínez Sopena, Pascual, La Tierra de Campos Occidental. Poblamiento, poder y comunidad en el siglo X al XIII, Valladolid, Institución Cultural Simancas, 1985, pág. 116.

52 El reconocimiento de una identidad territorial - en este caso el reconocimiento del valle de Cueza como representación de una entidad territorial- podría ser el reflejo de una realidad comunitaria anterior (ESCALONA, «Territorialidades e identidades locales», pág. 74).

53 C. Wickham insiste en este aspecto en referencia al entorno de Lucca en WICKHAM, Framing the Early Middle Ages, pág. 392.

54 CDS I, doc. 318. Vid. infra, págs. 389-390. 
Estas transacciones se realizaron en junio del año 977 y en abril del 978. Si consideramos el conjunto de nombres que aparecen en ambos documentos, nos encontramos con que varios de ellos coinciden. Algunos aparecen en ambas listas de testigos; otros lo hacen en uno como propietarios y en otro como testigos; en dos casos, los vicarios del primer documento figuran como testigos en el segundo. Ninguno de ellos aparece ni en los documentos de Ramiro II, ni luego en los de los Banu Gómez. Aunque no se pueda identificar cada uno de los nombres repetidos con una sola persona, sí podemos plantear, como hipótesis, que nos encontramos ante un grupo de propietarios locales que participaban de los negocios de sus vecinos, a veces como testigos y otras, en el caso de los vicarios, como representantes de otros propietarios, y que actuaban al margen de los personajes que reclamaban el dominio último sobre el espacio ${ }^{55}$. Esta escala de acción habría influido en el capital social y en las expectativas de cada uno de los individuos que participaban de ella y, por lo tanto, habría condicionado sus escalas de acción particulares.

Hay que tener en cuenta, además, que estas prácticas estaban contenidas en un espacio geográfico limitado. Es fundamental considerar este factor, ya que las distancias habrían definido las posibilidades de relación entre los miembros de la comunidad y, por lo tanto, de producción y reproducción de la estructuración socioespacial de la misma ${ }^{56}$. En este sentido, podríamos decir que las prácticas sociales que se desarrollaban en este ámbito geográfico generaban una dinámica local que estructuraba el espacio y le daba la cohesión que manifestaría la pervivencia de su identidad territorial. Esas prácticas serían, por lo tanto, constitutivas dicha identidad. Esta se plasmaba en la representación — proyección inmaterial — del espacio bajo el término «Cueza». El hecho de que esta identidad fuera reconocida por otros sujetos probaría la capacidad de resistencia de la sociedad local que, inicialmente, habría mantenido una escala de acción y una lógica propia después de haber sido integrada en el territorio de Carrión ${ }^{57}$. ¿Es posible discernir algo similar en el caso del valle de Trigueros? Los cuatro documentos de los que disponemos muestran un patrón complejo en el que la identificación de nombres de propietarios y testigos resulta más incierta aún, si bien la presencia repetida de varios antropónimos permite, al menos, especular con la idea que también existían prácticas sociales simi-

55 DAVIES, Small Worlds, pág. 128.

56 DAVIES, Small Worlds, pág. 125.

57 MARTíN VISO, Iñaki, «Espacios sin Estado: los territorios occidentales entre el Duero y el Sistema Central (siglos VIII-IX)», en MARTín VISO, Iñaki (ed.), ¿Tiempos oscuros? Territorios y sociedad en el centro de la Península Ibérica (siglos VII-X), Madrid, Sílex, 2009, págs. 134-135. Por supuesto, en un estudio que contemplara una duración más larga sería necesario comprobar si esta situación se habría mantenido en el tiempo. 
lares, posiblemente insertas en el marco de espacios de dominación señorial ${ }^{58}$. Finalmente, a partir de aquí podríamos preguntarnos si la pervivencia de estas formas de representación del espacio en las fuentes refleja el mantenimiento de este tipo de relaciones socioespaciales o si, en algún momento, pasaron a representar marcos territoriales formalizados e impuestos desde arriba.

Como he señalado, en ambos casos se observa la penetración de actores externos que, mediante la adquisición de tierras, socavaban la base material sobre la que se asentaba la capacidad de acción de los miembros de la sociedad local e introducían un nuevo patrón de relaciones sociales. El monasterio de San Ciprián era uno de esos actores externos ${ }^{59}$. Su abad, Martín, aparece comprando tierras en el momento en que una situación coyuntural exacerbaba las consecuencias de las contradicciones inherentes a la reproducción del modo de vida campesino. La compraventa, además de propiciar la integración de los bienes en el dominio monástico, constituía un nexo entre dos escalas diferentes en tanto que representaba la conjunción de dos capacidades de acción. Por un lado estaba la de los campesinos, en la medida en que, por perjudicial que pudiera resultar para sus intereses a medio o largo plazo, la venta de tierras no dejaba de ser una de las posibilidades que comprendía su capacidad de acción. Por otro lado, estaba la del monasterio.

Los elementos que condicionaban la capacidad de acción de la comunidad monástica eran distintos de los que limitaban o posibilitaban la acción campesina, aunque existían elementos comunes. Por ejemplo, los monasterios no dejaban de depender de factores económicos. Su capacidad de comprar tierras se habría visto condicionada, entre otras cosas, por la disponibilidad de un excedente con el que realizar el pago. No obstante, las diferencias entre ambas escalas son sustanciales, y esto no solo es debido a que los pequeños campesinos tuvieran una menor capacidad económica. Por ejemplo, los monasterios podían ejercer una importante presión sobre la propiedad campesina o incluso sobre la de grupos familiares de mayor preeminencia económica y social. Esta presión se basaba en su capital social y simbólico ${ }^{60}$. En algunos

58 Carlos M. Reglero de la Fuente trata de manera específica la cuestión de la presencia aristocrática y los señoríos en el valle de Trigueros. Véase REGLERO DE LA FUENTE, Los señoríos de los Montes de Torozos.

59 Los dominios de los grandes centros monásticos palentinos han sido ya estudiados por otros autores. Sin ánimo de exhaustividad, y dada la importancia de los monasterio de San Isidro de Dueñas o de San Zoilo de Carrión, sirvan de ejemplo, respectivamente, REGLERO DE LA FuENTE, Carlos M., El monasterio de San Isidro de Dueñas en la Edad Media. Un priorato cluniacense hispano (911-1478). Estudio y colección documental, León, Centro de Estudios e Investigación San Isidoro, 2005; PÉREZ CELADA, Julio A., El monasterio de San Zoilo de Carrión. Formación, estructura y decurso de un señorio castellano-leonés (siglos XI al XVI), Burgos, Universidad de Burgos, 1997.

60 GuERrEAU, Alain, «Structure et évolution des réprésentations de l'espace dans 1'Haut Moyen Age Occidental», en Uomo e spazio nell'alto medioevo. 50 Settimane di Studio del 
casos, los grupos aristocráticos y los reyes se servían de ellos para hacer efectiva su influencia a nivel local ${ }^{61}$. Esto suponía un beneficio para los monasterios, ya que el patronazgo implicaba habitualmente la donación de tierras. Además, reforzaba su prestigio y los convertían en el objeto de atención de otros actores, quienes, mediante donaciones, podían intentar vincularse a las redes de patronazgo de las que participaban los monasterios. El capital simbólico también podía influir en el volumen de donaciones recibidas y potenciar el crecimiento patrimonial ${ }^{62}$. En definitiva, como ocurría en los casos anteriores, el proceso de producción de un espacio monástico, en tanto que escala distintiva con condicionantes propios, dependía del juego de relaciones sociales del que participaban los monasterios ${ }^{63}$.

Por otro lado, la inalienabilidad de los bienes monásticos podía, en principio, revertir en un incremento de su capacidad de acción. Y digo en principio porque en la práctica nos encontramos tanto con usurpaciones de tierras eclesiásticas como con cenobios que vendían sus propios bienes. No obstante, gozaban, como institución, de mayores posibilidades de conservar su patrimonio. Esto podía facilitar la acumulación de propiedades, lo que se podía traducir en un aumento de los beneficios materiales derivados de la producción de esas tierras. Además, contribuía a potenciar su posición social en todos los niveles. Allí donde los monasterios e iglesias se asentaban o tenían propiedades, la presencia patrimonial continuada los convertía en una constante en el juego de relaciones sociales de otras comunidades de población ${ }^{64}$. En otras palabras, los centros eclesiásticos formaban parte de las expectativas que conformaban la lógica de otros grupos sociales ${ }^{65}$. Esto se veía reforzado por mecanismos tales como la producción de memoria mediante la redacción y manipulación de documentos ${ }^{66}$. En

Centro Italiano di Studi sull'Alto Medioevo, Spoleto, 4-8 aprile, 2002, 2 vol., Spoleto, Centro Italiano di Studi Sull'Alto Medioevo, 2003, pág. 107.

61 Desde la perspectiva del poder regio, BERNHARDT, John W., Itinerant Kingship \& Royal Monasteries in Eary Medieval Germany c. 936-1075, Cambridge, Cambridge University Press, 1993. En esta zona, Dueñas — al margen de Sahagún — fue el principal beneficiario de la acción regia en la primera mitad del siglo X (REGLERO DE LA FUENTE, El monasterio de San Isidro de Dueñas, docs. 1, 2, 3, 4, 7, 8).

62 MARTín ViSO, Iñaki, «Monasterios y redes sociales en el Bierzo altomedieval», Hispania, 71/237 (2011), pág. 12.

63 MARTín VISO, «Monasterios y redes sociales».

${ }^{64}$ Rosenwein, Barbara H., To Be the Neighbor of Saint Peter. The Social Meaning of Cluny's Property, 909-1049, Ithaca, Cornell University, 1989.

65 A. Guerrea señala que la efectividad del dominio dependía en parte de la interiorización de esta estabilidad espacial (GUERREAU, «Structure et évolution des réprésentations de l'espace», pág. 106).

66 E.g.: Peterson, David, «Reescribiendo el pasado. El Becerro Galicano como reconstrucción de la historia institucional de San Millán de la Cogolla», Hispania, vol. LXIX, 233 (2009), págs. 653-682. 
conjunto, todo ello generaba mayores posibilidades de imposición de relaciones de dominación y de percepción de rentas. Ahora bien, no debemos olvidar que, cuando esto ocurría, las condiciones de subordinación de los distintos espacios sociales englobados en el dominio monástico podían variar en función de cada situación particular, ni tampoco que las ambiciones de los monasterios podían entrar en conflicto con las de otros actores.

En algún momento antes del año 967, Flayna, soror de un convento en Monzón, y su hermano Ioannes, frater del monasterio de Cozuelos, decidieron fundar el monasterio de los Santos Justo, Pastor y Pelayo, con el fin de abrazar la vida monástica y de evitar que su pariente Juliano cayera en peca$\mathrm{do}^{67}$. El documento que recoge esta fundación narra la entrega de dicho monasterio al de Santa Eufemia de Cozuelos, que se ubicaba en la misma zona - sub castellum Eburi. El hecho de que Juliano no aparezca como ejecutor o confirmante de esta donación parece indicar que para entonces ya había muerto. La fundación de un centro religioso revela que el grupo tenía una cierta importancia económica en la zona. Lo mismo ocurría con el monasterio de Santa Eufemia. La base para la expansión y reproducción de cualquiera de estos dominios dependía, de manera inmediata, de los mismos recursos económicos y sociales, por lo que las relaciones entre ambos eran potencial, aunque no necesariamente, conflictivas. Bajo esta luz, el hecho de que Ioannes, que quizá como monje se habría visto obligado a entregar su parte de la herencia a la comunidad monástica a la que pertenecía, abandonara Santa Eufemia, se podría interpretar como un desafío a las ambiciones económicas que este monasterio pudiera tener sobre esos bienes. Pero las ambiciones de Santa Eufemia podían apuntar más alto. A fin de cuentas, englobar las propiedades de Juliano y sus parientes le habría permitido convertirse en el principal actor en la zona. Esto habría llevado al grupo familiar a intentar reforzar sus derechos sobre sus propiedades. En este sentido, la fundación del monasterio de los Santos Justo, Pastor y Pelayo se podría interpretar como la producción de un espacio de resistencia al que el carácter religioso dotaba de un componente simbólico.

A pesar de este esfuerzo, la competencia por las tierras y el capital social se saldó favorablemente para Santa Eufemia. Aunque no sabemos las razones que finalmente motivaron la donación del monasterio de los Santos Justo,

67 Guerrero Lafuente, M. ${ }^{a}$ Dolores y Álvarez Castillo, M. ${ }^{a}$ Angustias, «Los inicios del monacato en Palencia: Santa Eufemia de Cozuelos», en Actas del III Congreso de Historia de Palencia, Palencia, Diputación Provincial, 1995, págs. 178-180, doc. 3. Sobre iglesias y monasterios propios, LORING GARCíA, María Isabel, «Nobleza e iglesias propias en la Cantabria alto-medieval», Studia Historica. Historia Medieval, 5 (1987), pág. 89-121; MARTín VISO, Iñaki, «Monasterios y poder aristocrático en Castilla en el siglo XI», Brocar, 20 (1996), págs. 91-133. 
Pastor y Pelayo, lo cierto es que el monasterio de Cozuelos no se veía condicionado por los procesos de fragmentación de la propiedad que hacían peligrar la transmisión de bienes y prestigio dentro del grupo aristocrático. Además, podía hacer uso de los beneficios derivados de las donaciones en otros ámbitos geográficos ${ }^{68}$. No obstante, el hecho de que, en último término, el intento de Juliano y sus parientes fracasara, no implica que no fuera significativo. El monasterio de Santa Eufemia se vio obligado a asumir los condicionantes que implicaba el hecho de que las propiedades de Juliana y su familia hubieran sido articuladas en torno a un centro monástico. El resultado, es decir, la escala de acción definida en base a los recursos materiales y sociales de los que disponía el monasterio de Cozuelos tras la absorción de los bienes del grupo familiar de Juliano, fue, por tanto, fruto de la síntesis de sus respectivas capacidades de acción.

Debemos también considerar la presencia en la zona de otros monasterios de mayor entidad cuya escala de acción se caracterizaba por otros elementos. Tal sería el caso de San Isidro de Dueñas, Santa María de Aguilar de Campoo o, más tardíamente, San Zoilo de Carrión, pero también Sahagún, que tenía importantes propiedades. Esos elementos se derivaban, en parte, de las posibilidades que les ofrecían los procesos prolongados de acumulación de propiedades de los se beneficiaron - aunque en distintos tiempos y con distintos ritmos-, que les permitieron, por ejemplo, llevar a cabo una expansión patrimonial por distintos ámbitos geográficos ${ }^{69}$. Gracias a ello, podían desarrollar estrategias de gestión orientadas a la incorporación de ámbitos productivos complementarios. Esto podía dar lugar a un patrón de propiedad disperso, pero coherente con una determinada lógica económica ${ }^{70}$. No por ello debemos dejar de ver el dominio monástico como un espacio social único, aunque diverso, definido por, y articulado en torno a los distintos vínculos económicos y sociales que ligaban las distintas propiedades con el monasterio. Además, la concesión de inmunidades o el desarrollo de una capacidad jurisdiccional podían reforzar el componente normativo de esos vínculos. En este sentido, podríamos decir que los dominios monásticos constituían auténticos ensamblajes caracterizados por el ejercicio de una autoridad sobre un determinado doc. 2.

68 Guerrero lafuente y Álvarez Castillo, «Los inicios del monacato en Palencia»,

69 Me remito a los estudios particulares para cada caso. Respectivamente, según el orden en que se recogen en el texto: REgLERo DE LA FUENTE, El monasterio de San Isidro de Dueñas; PÉReZ CEladA, El monasterio de San Zoilo de Carrión; GónZAlez FAuve, María Estela, La orden premostratense en España. El monasterio de Santa María de Aguilar de Campoo (siglos XI-XV), Aguilar de Campoo, Centro de Estudios del Románico, 1992; MíngueZ, José María, El dominio del monasterio de Sahagún en el siglo X. Paisajes agrarios, producción y expansión económica, Salamanca, Universidad de Salamanca, 1980.

70 Considérese, en especial, MíNGUEZ, El dominio del monasterio de Sahagún. 
territorio y por un marco normativo propio ${ }^{71}$. Controlaban un ámbito geográfico sobre el que tenían aspiraciones exclusivistas ${ }^{72}$; podían propiciar la institucionalización de una serie de normas ${ }^{73}$; y desplegaban su autoridad gracias a los recursos que obtenían tanto de la producción económica como de los aspectos sociales, normativos y simbólicos de su dominio.

Más adelante veremos cómo los monasterios podían funcionar como nodos en las redes económicas y sociales definidas por las escalas de acción de mayor complejidad. Antes, sin embargo, debemos considerar con más detenimiento una cuestión que ha aparecido en este epígrafe: el caso de aquellos personajes que, mediante donaciones, se vinculaban a instancias sociales superiores. Tal era el caso de Iunez Mohomatel, quien, como vimos, realizó una donación de bienes a Ramiro I $^{74}$. Hasta el momento, los distintos actores que he considerado parecían tender hacia la acumulación de propiedades, en la medida en que la base material constituía un condicionante fundamental - aunque no exclusivo- de su capacidad de acción. ¿Cómo entender entonces este otro tipo de acciones, aparentemente contrarias a las lógicas de producción y reproducción de las escalas consideradas hasta ahora?

En el año 915, Ramiro, hijo de Alfonso III, donó a Sahagún media villa que había obtenido de Teodisclo en el entorno de Cansoles ${ }^{75}$. Más adelante, en el año 945, el obispo Oveco de León confirmó las donaciones que el monasterio de Sahagún había recibido tanto de Ramiro como de Agilina, la esposa de Teodisclo, quien le había entregado la iglesia de San Felices en Ceón posiblemente una iglesia propia ${ }^{76}$ - Teodisclo y su familia aparecen como propietarios de bienes de cierta relevancia — una villa y una iglesia- y sus tierras constituyen, además, una referencia espacial importante en el entorno de Ceón ${ }^{77}$. Esto, unido al hecho de que se relacionaran directamente con los miembros de la monarquía, nos transmite la idea de que se trataba de un gru-

71 Me baso en la noción de Saskia Sassen de ensamblaje de Territorio, Autoridad y Derechos (Sassen, Saskia, Territory, Authority and Rights. From Medieval to Global Assamblages, Princeton, Princeton University Press, 2006). En lugar de derechos, para la realidad medieval creo más adecuado hablar de «marco normativo» en el sentido que le da Godelier en relación con la propiedad y la explotación productiva del territorio a través de su apropiación (GODELIER, Lo ideal y lo material, págs. 100-106).

72 En línea con la noción de territorio propuesta en SACK, Robert D., Human Territoriality. Its Theory and History, Cambridge, Cambridge University Press, 1986, págs. 19-20.

73 Entendido como la formalización de unos usos sociales que no necesariamente habían de estar codificados por escrito.

74 CDS I, doc. 129.

75 CDS I, doc. 12. En el documento se nos dice que Ramiro la había obtenido por herencia de Teodisclo. En el documento de confirmación (CDS I, doc. 101), se especifica que había sido consecuencia de una profiliación.

76 CDS I, doc. 101.

77 CDS I, docs. 16 y 120. 
po familiar con un cierto grado de relevancia social. Este prestigio se habría asentado sobre una base material y un capital social relativamente importante en su entorno. Como vimos en los casos anteriores, la transmisión intergeneracional de bienes suponía un riesgo para el dominio familiar, puesto que la herencia podía fragmentar la base material del mismo. ¿Cómo entender entonces que Teodisclo se desprendiera de media villa? Esta acción solo cobra sentido si consideramos el beneficio que, en otros términos, le habría reportado enajenar parte de su patrimonio.

La escala de acción de Teodisclo, tal y como se ha planteado, no dependía exclusivamente del dominio directo que pudiera ejercer sobre sus bienes. $\mathrm{Su}$ posición social le habría garantizado una influencia sobre las personas de su entorno, por lo que, gracias a su capital social, su capacidad de acción se habría irradiado más allá del espacio que estaba directamente bajo su control. Podríamos pensar que esta preeminencia se traducía, por ejemplo, en que los campesinos del entorno recurrieran a él, como en el valle de Trigueros lo hacían al monasterio de San Ciprián, para que les hiciera préstamos o les comprara sus bienes. Además de constituir una oportunidad para la ampliación del patrimonio, de ello se habrían podido derivar relaciones de dependencia económica. Otra posibilidad es que, debido a su posición social, Teodisclo hubiera ejercido como mediador en la resolución de las disputas locales. Todo ello habría hecho de él un elemento atractivo para aquellos actores que, como la monarquía, buscaban canales que les permitieran llevar a cabo un dominio efectivo sobre el espacio. Vincularlos a sus redes suponía integrar también los espacios que controlaban o sobre los que ejercían su influencia. A su vez, personajes como Teodisclo se habrían beneficiado de la inserción en estas redes de poder, ya que ello podía contribuir a reforzar su posición e, incluso, a formalizar el ejercicio de su autoridad.

Por otro lado, la vinculación con la monarquía tuvo lugar mediante una profiliación. Más allá de la ficción del parentesco que ello implicaba, esto nos indica que el vínculo social se estableció a través de la transmisión de propiedades. Gracias a su capacidad para disponer de estos bienes, Teodisclo hizo uso de esas "políticas de la tierra» que se han descrito, paradigmáticamente, como una práctica de los reyes, pero de las que podían hacer uso distintos actores $^{78}$. La profiliación también refleja la importancia que para la monarquía, que luego donaría estas tierras a Sahagún, tenía la adquisición de propiedades en las zonas que aspiraba a controlar, ya que podían ser necesarias para favorecer a los actores locales, tanto eclesiásticos como laicos. Ambos elementos se encuentran documentados en otras escalas de acción, como la de los grupos aristocráticos. La donación de la villa de Calzadilla de la Cueza que García Gómez realizó en el año 984 tuvo como beneficiarios a dos perso-

78 WiCKHAM, Framing the Early Middle Ages, pág. 58. 
najes, Gonzalo y Gotina ${ }^{79}$, a los que el documento les atribuye la capacidad de ofrecer por ella un caballo y una silla de plata, valorados cada uno en trescientos sueldos, y un freno valorado en cien sueldos. Estas cantidades podrían interpretarse como una manifestación de las obligaciones contraídas y de la importancia que ambas partes atribuían a esta relación, así como indicio de la relevancia de la que Gonzalo y Gotina disfrutaban en su entorno.

En definitiva, la disminución de la base material del dominio de Teodisclo se habría visto compensada gracias a que su vinculación con la monarquía habría reforzado su capital social. Esto le habría dado una mayor capacidad de influencia a nivel local y, como consecuencia de ello, mayores posibilidades económicas. El componente relacional - es decir, la medida en que la producción de estos espacios dependía de la red de relaciones sociales en las que se imbricaban los agentes que reclamaban una autoridad sobre los mismos - jugaba en estos casos un papel muy importante, aunque no suficiente. La base material resultaba esencial, primero, en la constitución de la desigualdad social sobre la que se construía la preeminencia en el entorno; y, segundo, en el mantenimiento de esta posición. El refuerzo social no eliminaba los problemas que conllevaba la transmisión intergeneracional de propiedades y prestigio. Esto no implica que estas élites estuvieran abocadas a la desaparición. Es cierto que, en el caso del grupo familiar de Teodisclo, su influencia parece diluirse. No podemos construir el argumento de su desaparición sobre la base del silencio documental, pero lo cierto es que, aunque sabemos que sus hijos heredaron la propiedad de las tierras - aunque no sabemos si de manera colectiva o si el patrimonio se fragmentó a su muerteninguno de ellos destaca en la documentación posterior ${ }^{80}$. Por el contrario, el grupo familiar de Gonzalo y Gotina parece haber consolidado su posición durante al menos unas generaciones, ya que su nieta, Mumadonna, aparece donando bienes a Sahagún en la segunda mitad del siglo XI ${ }^{81}$.

\section{Los monasterios y los dominios de los grandes grupos aristocráticos}

Antes apunté que los monasterios podían funcionar como elementos constitutivos de las redes económicas y sociales definidas por las escalas de acción de los grandes grupos aristocráticos. Es necesario analizar ahora con más detalle esta última cuestión, ya que los dominios de los grupos aristocráticos, que muchas veces se manifiestan en el siglo XI como grandes agregados de propiedades dispersas, constituyen uno de los elementos característicos en la

\footnotetext{
79 Sabemos que se trataba de estos personajes gracias a CDS II, docs. 590 y 703 .

80 CDS I, doc. 76.

81 CDS II, docs. 590 (1057.04.17) y 703 (1071.08.03).
} 
región en esa época, así como la base económica y social de quienes, en la mayor parte de los casos, ejercerían el poder sobre las circunscripciones que comienzan a definirse entonces. Hay que señalar también que, en algunas ocasiones, conocemos la extensión y diversidad de los dominios aristocráticos gracias a las grandes donaciones que realizaron a determinados centros monásticos como parte de los mecanismos de creación de memoria. Este aspecto ha sido estudiado por autores como P. Martínez Sopena, por lo que no entraré aquí en mayor profundidad ${ }^{82}$.

En el año 1049, Teresa Muñiz y sus hijos realizaron una amplia donación al monasterio de Sahagún ${ }^{83}$. Se trataba de un grupo aristocrático con propiedades dispersas entre el Pisuerga y el $\mathrm{Cea}^{84}$. El documento es muy amplio y no la analizaré en base al hecho que describe - la donación en sí misma-, sino por la información que contiene sobre una situación anterior. Me interesa centrarme tan solo en parte de los bienes donados, concretamente en los que se encontraban en dos territorios ubicados en el norte de la actual provincia de Palencia: Mudá y Vergaño. El elemento central de la donación en esta zona era el monasterio de los Santos Justo y Pastor, que se ubicaba en el territorio de Mudá. La pervivencia del topónimo y la descripción de sus términos nos permiten situarlo al sureste de Quintanaluengo. La enumeración de sus límites contiene abundantes menciones a tierras arables, incluyendo no solo aquellas que quizá pertenecían al monasterio, sino también a unas «terras aratiles de uillanos». A ello se suman una serie de tierras en el entorno del Pisuerga, que se describen también como arables y se categorizan como sernas. Junto con los bienes donados en Mudá, Teresa Muñiz y sus hijos donaron ocho prados en el territorio de Vergaño, el actual valle de Vergaño (Palencia).

Los territorios de Mudá y Vergaño son geográficamente muy similares. Se trata de dos valles paralelos, relativamente estrechos y articulados por un curso fluvial. El entorno de Quintanaluengo es, por el contrario, una zona de vega apta para el cultivo, como indicarían las menciones a esas terras aratiles. Constituía un pivote natural de articulación entre Mudá y Vergaño. Esta condición es la que hace del monasterio un elemento tan interesante en el proceso de producción del espacio aristocrático en la región. Aunque el documento no

82 Martínez Sopena, Pascual, «Los espacios de poder de la nobleza leonesa en el siglo XII», en Sesma MuÑOz, José Ángel y LALIENA CORBERA, Carlos (coords.), La pervivencia del concepto. Nuevas reflexiones sobre la ordenación social del espacio en la Edad Media, Zaragoza, Universidad de Zaragoza, 2008, págs. 219-258.

83 CDS II, doc. 530. El documento es una más de un grupo de donaciones de esta época en la región, realizadas por miembros de la aristocracia y grandes propietarios, que entregaban bienes dispersos en beneficio de un monasterio. E.g.: CDS II, doc. 615.; RUIZ ASENCIO, José Manuel, RUIZ ALBI, Irene y HerRero JimÉnEZ, Mauricio, Colección documental del monasterio de San Román de Entrepeñas (940-1068), León, Centro de Estudios San Isidoro, 2000, doc. 2.

${ }^{84}$ CDS II, docs. 467, 516, 527, 598, 599, 700. 
nos permite reconocer el tipo de dedicación económica de la zona de valle del territorio de Mudá, podemos pensar que no sería muy diferente de la que encontramos en el caso de Vergaño, donde no se menciona ninguna tierra arable y sí, por el contrario, varios prados. Se habría tratado, por tanto, de zonas con una probable dedicación ganadera o, en todo caso, con un tipo de producción diferente a la de la zona de vega del Pisuerga, donde encontramos una orientación agrícola. No sabemos si las posibilidades económicas de esta complementariedad de las que gozaba, por su ubicación, el monasterio, estaban siendo aprovechadas con anterioridad a la intervención aristocrática. Lo que es indudable es que esta potenció la creación de lazos económicos que atravesaban las divisiones geográficas y territoriales. El monasterio de los Santos Justo y Pastor constituía un punto de apoyo con el que, mediante la combinación de ámbitos productivos y la concentración del acceso a los recursos, se podía alcanzar una escala económica superior a la que funcionaba en el marco de los territorios originales. Vemos, por tanto, cómo el proceso de producción de la escala de acción del grupo aristocrático dependía de su capacidad para construir nexos mediante los que englobar escalas de acción de menor complejidad. El dominio del monasterio - en definitiva, la escala de acción del propio monasterio- resultaba esencial para articular los beneficios económicos derivados del control de tierras en la zona. Por tanto, la consolidación de esta escala de acción aristocrática dependía, entre otros factores, de la dialéctica de la acción productiva sobre los espacios naturales impulsada por y a través del monasterio. En otros casos, podía depender directamente de la adquisición de las tierras de pequeños propietarios, o de villas o partes de villas ${ }^{85}$.

Además de las tierras en los valles, la donación incluía otras propiedades que se encontraban en el entorno inmediato del monasterio y que eran, en su mayoría, sernas de dedicación agrícola. El hecho de que se tratara de sernas quizás indique una infiltración señorial progresiva en la zona ${ }^{86}$. El grupo aristocrático habría ido acumulando o habría adquirido directamente los derechos que terminarían por darle el control sobre estos espacios, que quizás habían sido anteriormente objeto de una explotación comunitaria, pero cuya producción se reorientó para beneficio aristocrático y monástico mediante la canalización del excedente a través del monasterio de los Santos Justo y Pastor. Podríamos hablar de una doble reorientación: la del marco normativo local, que habría regulado el acceso a la explotación de las sernas por parte de los grupos campesinos, y la de la lógica productiva campesina y del monasterio mediante la implantación de una nueva lógica: la aristocrática. La dimensión normativa que

85 E.g.: CDS II, doc. 467; PÉREZ CeladA, Julio A., Documentación del Monasterio de San Zoilo de Carrión (1047-1300), Burgos, Ediciones J.M. Garrido Garrido, 1986, doc. 3.

86 Sobre las sernas, véase Botella POMBO Esperanza, La serna: ocupación, organización y explotación del espacio en la Edad Media (800-1250), Santander, Tantin, 1998. 
podría apreciarse detrás de la mención de las sernas se observaría también en el caso de las divisas. Si las interpretamos como derechos de uso sobre determinados espacios, la posesión de divisas y su apropiación y transferencia implicaban un cambio en la distribución de los derechos de explotación ${ }^{87}$.

En otros casos, los marcos normativos aparecen recogidos de manera más explícita. En la donación de Teresa Muñiz se consignan una serie de exenciones fiscales y se prohíbe la entrada de distintos agentes - el merino y el sayón-, lo que podría representar el marco normativo bajo el que había funcionado el dominio aristocrático hasta entonces ${ }^{88}$. Puesto que el documento se conserva en una copia posterior, cabe la duda de que se trate de una interpolación. En cualquier caso, nos permite pensar que en estos espacios confluían, o podían llegar a confluir, un dominio económico y social y un dominio jurisdiccional. El aspecto normativo se podía expresar también de otras maneras. Por ejemplo, Fronilde Fernández se entregó al monasterio de Santa María de Aguilar de Campoo en el año $1042^{89}$. Acompañó su entrada en el monasterio de la donación de un monasterio en la villa de Zalima, «cum quanto pertinet... si quomodo pertinet ad illo monasterio et ad illa uilla», es decir, aparentemente, conforme a unos derechos o normas que regulaban la propiedad de esos bienes. Estas cláusulas pueden tener un cierto carácter retórico, pero desvelan que las donaciones implicaban una reorientación de los marcos normativos. El reconocimiento de una realidad normativa anterior a la implantación de una autoridad de rango superior, se plasmara o no por escrito en las cláusulas documentales o en los fueros, era parte del proceso dialéctico de producción de las escalas de acción, ya que era a la vez limitador y posibilitador de la acción tanto campesina como aristocráti$\mathrm{ca}^{90}$. No obstante, la superposición de la autoridad aristocrática suponía también su penetración fiscal o judicial, lo que alteraba la circulación del excedente y los cauces de resolución de disputas en beneficio del señor. Por otro lado, la capacidad de anticipar la aplicación del marco normativo mediante recursos como la fórmula ad populandum o ad laborandum proyectaba la continuidad del dominio con independencia del cambio de persona al frente del mismo, con lo que la asociación entre un marco normativo progresivamente institucionalizado y el espacio físico en el que este era de aplicación se volvía mucho más estrecha ${ }^{91}$.

87 Álvarez Borge, Ignacio, Poder y relaciones sociales en Castilla en la Edad Media. Los territorios entre el Arlanzón y el Duero en los siglos X al XIV, Valladolid, Junta de Castilla y León, 1996, pág. 39.

88 CDS II, doc. 530.

89 Rodríguez De Diego, José Luis, Colección Diplomática de Santa María de Aguilar de Campoo (852-1230), Valladolid, Junta de Castilla y León, 2004, doc. 5.

90 Alfonso ANTÓN, «Campesinado y derecho».

91 E.g.: Rodríguez De Diego, Colección Diplomática de Santa María de Aguilar de Campoo, doc. 5 . 


\section{CONCLUSIÓN}

Este recorrido culminaría con la consideración más completa de los grandes dominios aristocráticos $\mathrm{y}$, finalmente, de la escala de mayor complejidad de la sociedad altomedieval que operaba en este espacio: la que definía el propio reino. Ambas escalas estaban íntimamente relacionadas por lo que, dada la amplitud que requeriría ese análisis, hacerlo escapa a las pretensiones de este trabajo, aunque se han presentado las que podrían ser las bases de dicho estudio. En cualquier caso, hemos visto cómo el reino no se podría considerar sin prestar una atención muy detenida a las escalas que englobaba y a los mecanismos de integración que le daban cohesión. Tampoco se puede concebir como una realidad inmutable, ya que participaba del mismo dinamismo que se ha descrito para el resto de escalas de acción.

A lo largo de este artículo se ha visto que las escalas de acción comprenden una serie de elementos constitutivos que se pueden analizar en base a criterios comunes, lo que permite valorar las diferencias entre cada una de ellas. La exposición ha tendido a enfatizar un gradiente de creciente complejidad en el que las sucesivas escalas presentadas englobaban escalas anteriores. Sin embargo, esto no significa necesariamente que el proceso diacrónico siguiera una línea única de estructuraciones particulares. Las diferencias entre un dominio aristocrático como el de los Banu Gómez y otro como el de Teresa Muñiz no dependían solo de las transformaciones internas de estas escalas, sino también de los cambios producidos en los elementos constitutivos de las mismas. Se trata, por tanto, de un proceso en el que se solapan distintas escalas no solo espaciales, sino también temporales. El conjunto de propiedades de Marcos y Emderia, el pequeño dominio de Teodisclo, el de Juliano, o el monasterio de los Santos Justo y Pastor, son realidades históricas subsumidas y a veces difícilmente reconocibles en el proceso general, pero constitutivas del mismo y en el que pueden operar con una lógica propia. Por ejemplo, algunos autores han destacado la gran capacidad de inserción y de pervivencia de la lógica campesina ${ }^{92}$. No obstante, dado que el marco campesino estaba imbricado en escalas interrelacionadas, el sentido último de su funcionamiento dependía de la configuración de estas relaciones. Habría también que iluminar la síntesis que se producía tras la imposición de las relaciones de domi-

92 MARTín ViSO, «Espacios sin Estado», págs. 134-135. Quizá herramientas conceptuales como el «modo de producción campesino» puedan ayudarnos a pensar mejor en las realidades socioespaciales anteriores a la inserción. WickHAM, Framing the Early Middle Ages, pág. 536. Considérese también la noción de «espacio no subalterno» propuesta en VIGIL-ESCALERA GuIRADO, Alfonso, "Granjas y aldeas altomedievales al norte de Toledo (450-800 D.C.)», Archivo Español de Arqueología, 80 (2007), pág. 242. 
nio, que daría lugar a la emergencia de una nueva lógica y un nuevo espacio social ${ }^{93}$.

Las escalas, por tanto, no se entienden en referencia a sí mismas, sino al conjunto de interrelaciones del que forman parte. Hemos visto cómo las prácticas sociales de las que participan los actores constituyen nodos de vinculación entre las distintas escalas y pueden producir cambios en la configuración de las bases materiales y sociales que las constituyen. Aunque algunas de estas prácticas fueran susceptibles de ser utilizadas por sujetos sociales de distinta condición, esto no significa que representen canales de articulación de relaciones sociales neutras. No debemos olvidar su carácter contradictorio y conflictivo, ni tampoco su incidencia en la creación, potenciación o consolidación de las desigualdades sociales ${ }^{94}$. Además, hay que tener en cuenta que podían tener un impacto diferente según en qué escala se hiciera uso de ellas. Finalmente, aunque no se ha desarrollado, se ha apuntado también cómo algunos actores podían recurrir a otros mecanismos de imposición o legitimación de las relaciones de dominio, aunque sobre la base de las capacidades básicas que se han descrito - los recursos materiales y el capital social-.

En definitiva, la caracterización en términos de escala, que implica una noción transversal de las diferentes capacidades de acción de los distintos sujetos sociales, podría ser una de las posibles estrategias para profundizar en el estudio, primero, de cómo las sociedades hispanas fueron alcanzando, tras un periodo de fragmentación, grados cada vez más altos de interrelación entre los distintos sujetos; y segundo, de cómo se formalizaron las relaciones de poder. Por un lado, porque nos permitiría atender a cada caso concreto con una discusión detenida de sus condicionantes socioespaciales, incluidos aquellos que, como la identidad o la percepción del espacio, etc., solo hemos podido tratar aquí de manera superficial. Por otro, porque nos dotaría de una serie de herramientas con las que trazar una comparación entre los distintos casos. En conjunto, nos ayudaría a analizar mejor el proceso de complejización que se aprecia en las sociedades hispanas altomedievales.

Fecha de recepción: 31-05-2011.

Fecha de aceptación: 23-04-2012.

93 SASSEN, Territory, Authority and Rights, págs. 26-32. Véase la idea de «tercer espacio» tal y como se plantea en MoRELAND, John, «Archaeology and Texts: Subservience and Enlightenment», Annual Review of Anthropology, 35 (2006), pág. 137.

94 Por ejemplo, la compraventa de divisas en el seno de grupos familiares podía propiciar la acumulación de bienes en manos de algunos miembros, en detrimento de otros, y potenciar desigualdades internas (LARREA CONDE, «Aldeas navarras y aldeas del Duero», pág. 149). 